\title{
¿Estatinas en Prevención Primaria?
}

\author{
Alexis Lama
}

Señor Editor:

Recientemente, la US Food and Drug Administration (FDA) ha extendido la aprobación del uso de rosuvastatina para reducir el riesgo de infarto del miocardio y de accidente vascular cerebral en personas sin evidencia de cardiopatía coronaria, con colesterol LDL normal, pero con niveles de proteína $\mathrm{C}$ reactiva ultrasensible aumentada, y al menos un factor de riesgo cardiovascular ${ }^{1}$. La recomendación de la FDA está apoyada en los resultados del estudio JUPITER, el cual señala una reducción del señalado riesgo de hasta un $44 \%$, con el uso de $20 \mathrm{mg}$ de rosuvastatina comparado con placebo, en pacientes sin cardiopatía coronaria, es decir como prevención primaria . Previamente, en sus guías del 2009, la Sociedad Cardiovascular de Canadá sobre prevención de Enfermedades Cardiovasculares en Adultos, había publicado recomendaciones similares.

La aceptación y consiguiente aplicación en la práctica médica de esta aprobación y guía, podría traer variadas consecuencias.

La más obvia es que los millones de nuevas personas alrededor del mundo que en los próximos años estarán tomando rosuvastatina, indicada por médicos crédulos y seguidores de la FDA, y de las guías, sobrepasará con creces la población total de nuestro país. Esto tiene mucha importancia, aparte del ingente costo que su uso conllevará, porque es sabido que esta droga no está exenta de efectos adversos, mismos que podrían ponerse en mayor evidencia cuando una población de tal magnitud y no seleccionada, ingiera por numerosos años esta droga. Esto cobra aún mayor importancia, con implicancias éticas, si el beneficio de tal conducta no fuese tan seguro como se ha publicado y difundido.

Otra consecuencia de la presente guía y aprobación, sería un gran aumento de la indicación médica a las personas para que midiesen su nivel de proteína $\mathrm{C}$ reactiva ultra- sensible.

Por esto, resulta de interés analizar con detalle y espíritu crítico el valor predictivo de la proteína $\mathrm{C}$ reactiva como factor de riesgo cardiovascular, como así mismo el mencionado estudio JUPITER.

Respecto a la proteína $\mathrm{C}$ reactiva, hay que señalar que un reciente meta análisis reportó sólo una modesta asociación entre proteica $C$ reactiva ultrasensible y riesgo cardiovascular, y en el mismo estudio JUPITER el valor predictivo positivo de tal parámetro resultó débil, $1.35 \%$. Y el diseño del estudio no permite sacar conclusiones válidas acerca del rol de la proteína $\mathrm{C}$ reactiva en el manejo clínico, ya que no hubo comparación entre sujetos con y sin proteína $\mathrm{C}$ reactiva, ni comparó ésta con otros marcadores de riesgo cardiovascular ${ }^{1}$. Tampoco se estudió si los sujetos con proteína $\mathrm{C}$ reactiva menor de $2.0 \mathrm{mg} / \mathrm{lt}$ podrían beneficiarse con el tratamiento.

En relación con la confiabilidad de los resultados del JUPITER, ha habido desde el inicio, una creciente polémica, encontrándosele importantes inconsistencias clínicas y epidemiológicas ${ }^{2}$, misma que parece prudente no desestimar sin un cuidadoso análisis de los datos presentados, más aún si se toma en cuenta que es el primer estudio de los financiados por la industria farmacéutica que en los últimos años mostró resultados favorables en cuanto a protección cardiovascular, después de una seguidilla de estudios con resultados desfavorables y de otros que por lo mismo, no se publicaron o se suspendieron, como el CASHMERE y el ACHIEVE, respectivamente.

Hay que hacer notar, que siempre este tipo de estudios enfatiza los riegos relativos para hacerlos más impresionantes al lector; sin embargo, en el JUPITER en realidad, se mostró que hubo que tratar 120 participantes por un periodo de 1.9 año, para prevenir un evento ${ }^{3}$.

Por otra parte, la suspensión prematura del estudio, levantó serias suspicacias, ya que se sabe que estas suspensiones tienden a inflar los beneficios de la droga en cuestión, 
subestiman los daños o efectos adversos, y permite que los resultados sean publicados precozmente, con la consiguiente ventaja en el mercado, y reducción en los costos del estudio.

Se esgrimieron razones éticas para la suspensión prematura del estudio, debido a la inequívoca reducción en la mortalidad cardiovascular: Sin embargo, si se analiza cuidadosamente la Tabla 3, de la publicación de noviembre 2008, se puede constatar, sorprendentemente, que la mortalidad cardiovascular (accidente vascular fatal más infarto del miocardio fatal) resultó idéntica en ambos grupos (12 vs 12), ya que se puede deducir de esa Tabla, que 9 participantes que recibieron rosuvastatina tuvieron infarto del miocardio fatal (31 con cualquier infarto menos 22 con infarto no fatal), y 3 murieron de accidente vascular cerebral (33 con cualquier accidente vascular cerebral menos 30 con accidente vascular cerebral no fatal). También llama la atención que la mortalidad por infarto haya sido tan baja, en general, y en especial en el grupo placebo (8.8\%) y mayor, casi tres veces más, en el grupo rosuvastatina (29\%). También resulta llamativo que en la Fig. 1, de la publicación primera en el NEJM del $2008^{4}$, la incidencia acumulada de muerte por cualquier causa, se prolonga hasta los 4,5 años, al final de los cuales las curvas entre el grupo rosuvastatina vs placebo se acercan bastante, pudiéndose especular que de no haberse suspendido el estudio precozmente, no habría sido posible detectar diferencias. Pero lo inexplicable resulta de constatar que en una publicación posterior, del $2009^{5}$, la misma Figura ha sido cambiada, truncada, y sólo se presenta el seguimiento hasta los 4 años, previo a la disminución de la separación de ambas curvas.

Parece adecuado, en general, mostrarse prudente frente a aprobaciones de la FDA y a recomendaciones provenientes de guías, habitualmente confeccionadas por expertos con conocidos conflictos de intereses, y en lo particular, mostrarse muy escéptico respecto a los resultados del JUPITER, que por lo demás, muestra serios conflictos de intereses de sus autores, y cuyo principal investigador está involucrado en la patente del examen de proteína $\mathrm{C}$ reactiva ultrasensible.

Por todo lo expuesto, y en conclusión, estimo que no resulta recomendable el uso rutinario de rosuvastatina en prevención primaria, como así mismo el uso masivo de proteína $\mathrm{C}$ reactiva como indicador de riesgo, $\mathrm{y}$ resulta importante para la práctica clínica considerar, que en general, el uso de estatinas en prevención primaria cardiovascular, aún en personas de alto riego, no encuentra sustento en la literatura, especialmente si consideramos un meta análisis reciente que ha incluido más de 65 mil pacientes, que no mostró beneficio con el uso de estatinas en disminuir todas las causas de mortalidad ${ }^{6}$.

\section{Referencias:}

1. Kaul S, Morrissey RP, Diamond GA. By Jove! What is a clinician to make of JUPITER? Arch Intern Med. 2010; 170: 107377.

2. De Lorgeril M, Salen P, Abramson J, Dodin S, Hamazaki T, Kostucki W, et al. Cholesterol lowering, cardiovascular diseases, and the rosuvastatin-JUPITER controversy: a critical reappraisal. Arch Intern Med. 2010, 170: 1032-36.

3. Hlatky M. Expanding the orbit of primary prevention--moving beyond JUPITER. N Engl J Med. 2008; 359; 21: 2280 - 82.

4. Ridker PM, Danielson E, Fonseca FA, Genest J, Gotto AM Jr,
Kastelein JJ, et al. Rosuvastatin to prevent vascular events in men and women with elevated C-reactive protein. $\mathrm{N}$ Engl J Med. 2008; 359: 2195-207.

5. Ridker P. The JUPITER Trial: Results, Controversies, and Implications for Prevention. Circ Cardiovasc Qual Outcomes. 2009; 2: 279-285.

6. Ray KK, Seshasai SR, Erqou S, Sever P, Jukema JW, Ford I, et al. Statins and all-cause mortality in high-risk primary prevention: a meta-analysis of 11 randomized controlled trials involving 65,229 participants. Arch Inter Med. 2010; 170: 1024-1031 